\title{
Motifs behind Using Sculptures, Objects and Paintings in Tragedies: A Review of Literary History
}

\author{
Farah Qamar* \\ University of Education, Pakistan
}

Submission: December 12, 2019; Published: January 30, 2020

*Corresponding author: Farah Qamar, University of Education, Pakistan

\begin{abstract}
This short review aims to show the use of sculptures, objects and paintings in some tragedies. Review of literature shows that dramatists used sculptures, objects and paintings in order to give voice and description of human suffering and calamities. All objects also specify that how man in general perceives tragedy and responds to tragic events. This review concludes that visual objects intensify suffering and elevate emotions into the hearts of subject and audience.
\end{abstract}

Keywords: Sculptures; Objects; Paintings; Tragedy

\section{Introduction}

The following extract is taken from Eliot's statement to describe that why tragedy plays a large part in many forms of literature and in sculpture, music, and painting. Tragedy, dedicated to painful actions, also interests, fascinates, absorbs us. It is not diverting, amusing; it is not for daily food or recreation, but no less it ministers to an active normal human interest. Behind the dialogue of Greek drama, we are always conscious of a concrete visual actuality, and behind that of a specific emotional actuality [1].

\section{A History of Archaic Greek Dramas}

Literature review shows that the most important period of art is Greek poetry. It is pioneer in representing tragedy in the form of sculpture, music, and painting. It involves vases and vessels and decorated with linear proto-geometric style. The geometric style is designed on triangles, zigzags, and with other similar shapes and shaped with strict system of proportion. The Black Sea basin and the Middle East had a noticeable Eastern interest and then used by Corinth ceramicists. Greek used this idiom more elaborately to express their motives like in the presentation of creatures like sphinxes, griffins and chimeras and gradually human figures were included in the paintings. Greek Classic Era is well known for its improvement in depicting human body in sculptures. These sculptures looked more real to life than paintings. In this era, subjects were widened with the figures of gods and goddesses. These sculptures further highlighted with the figures of Platonic "Canon of Proportions" in order to create an idealized human body and in the late classical era, first nude female body was painted. Parthenon was decorated to illustrate their religious buildings [2]. The purpose of using these arts by Corinth is emerged as a new idiom to describe (as discussed earlier) their motifs, creatures like sphinxes, griffins and chimeras (Figure 1). Gradually, this inspiration developed and became figurative. It was further developed by the inscription of animals and human figures. The history of Greek archaic shows that in the beginning of the time, Greeks were used to painting figures and human bodies to illustrate their motives and tragedy.

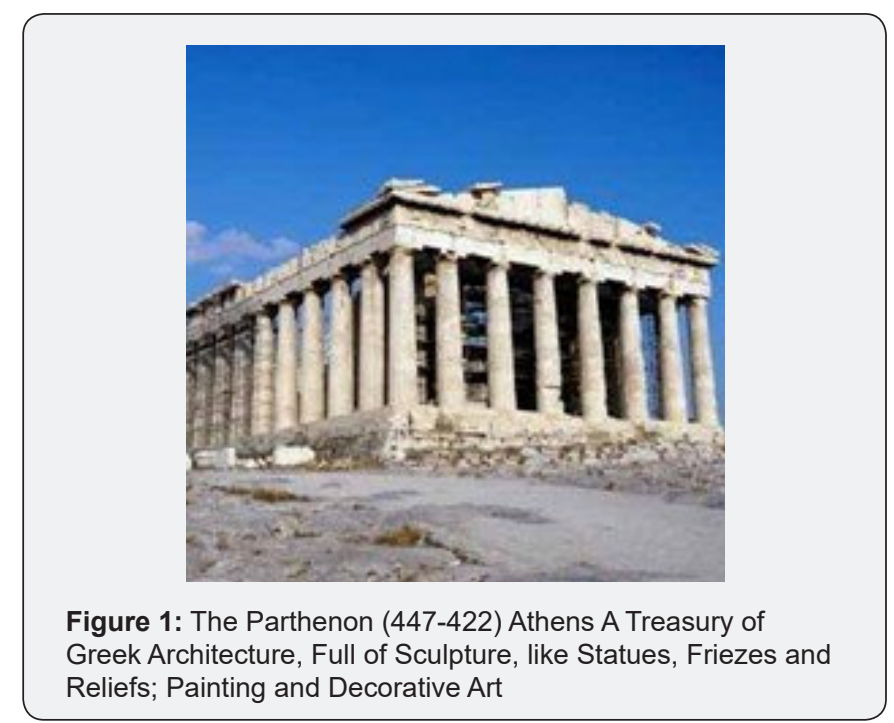



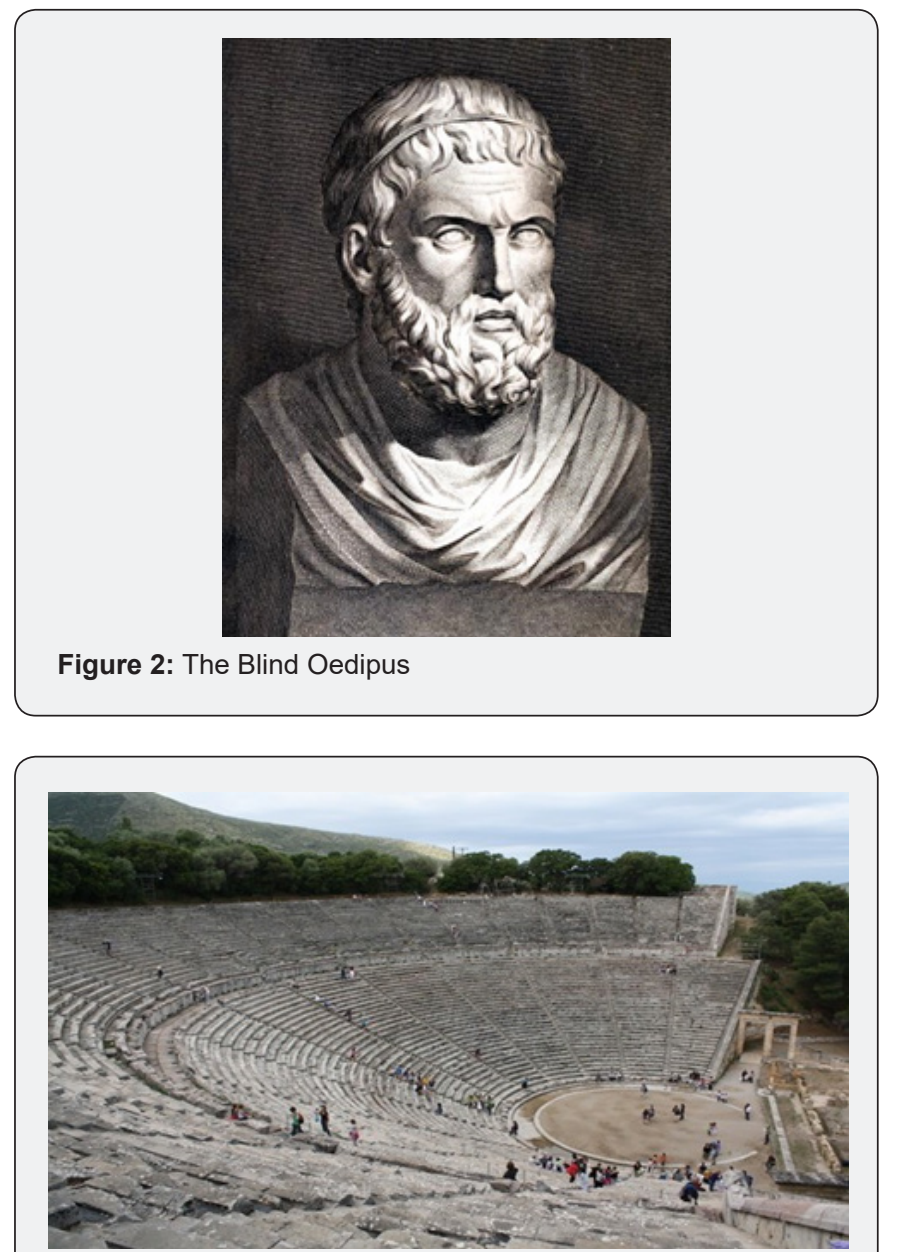

Figure 3: Ancient Greek Theater.

On the other hand, the truth which Oedipus discovered took him towards his fatal life. The truth marrying one's mother unknowingly is more unnatural than killing one's father. Likewise, as Oedipus blinds himself to avoid the truth is true to life because blinding one's self does not mean to wash one's brain. His blindness could not bridge a gap between him and his vision (Figure 2). Regarding staging of tragedies, it becomes clear that staging gives a clear picture to voice. It enhances and develops audience's interest. Taplin says that the meaning of the play, its where about and visuals captures audience's mind. As the origin of the drama is unique to Greek dramas, they used theater to translate their meanings [3]. Not only the staging is matter of significance, in fact the building and machinery also capture audience's interest (Figure 3).

\section{Shakesprean Drama}

Likewise, apart from the theatre, characters' movement, context of the story, objects, and attire always leave a permanent effect on audience's mind. The example is visible (Figure 4) in Hamlet while holding the skull; how he pondered and gestured.
Likewise, Lear holding dead Cordelia in his arms shows real life like tragedy. These staging are meaningful with sequence. Taplin (Figure 5) says that great dramas have universal appeal. Great dramas portray actions and human conditions through voices, objects and actions. No mode of human life is missed out in the dramas.

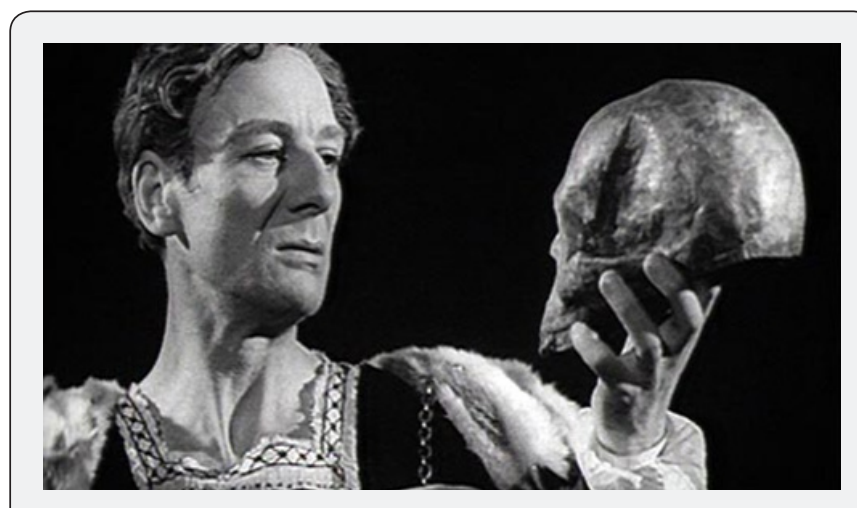

Figure 4: To Be or Not to Be.

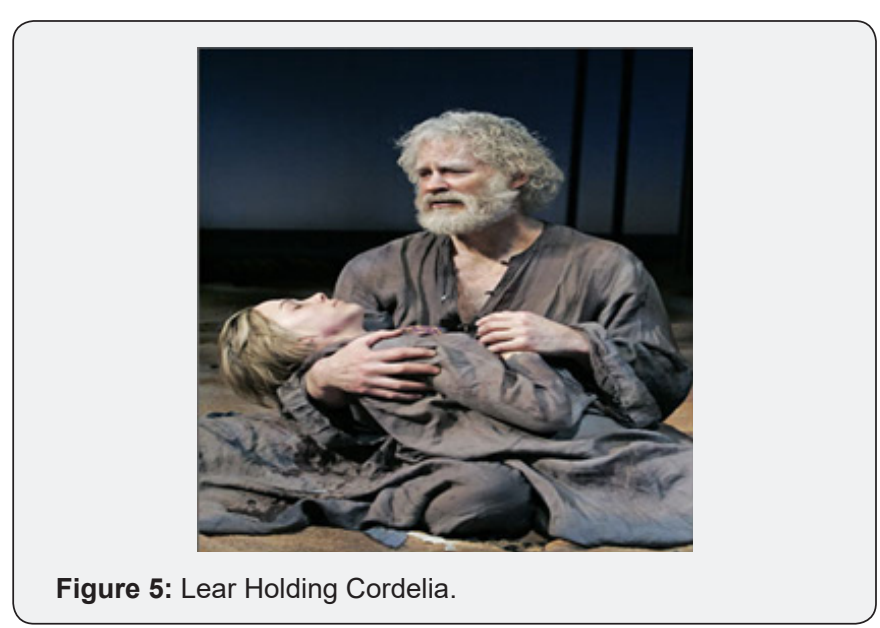

\section{Conclusion}

Tragedies in all aspects depict the dilemma of human life in general. Not only death scenes appeal us in fact every little object has its own significance in the tragedies. All tragedies have some little objects which become the cause of a tragedy. These objects are also true to life. Taplin [1] says. "Objects are important: they can define and substantiate people's roles, their standing, their way of life like a wedding ring, a lock of hair, a jester's skull, a hollow crown and a handkerchief spotted with strawberries". Interpreting Taplin's

statement, we can say that these objects played a significant role in the tragedies like skull in Hamlet and hander kerchief in Othello. No one can deny that these objects aroused audience's interest with long lasting effects similarly Oedipus' blindness and ancient Greek theater added fuel to the fire. 


\section{References}

1. Taplin $O$ (2003) Greek Tragedy in Action. London, Routledge.
2. Kitto DFH (2003) Greek Tragedy: A Literary Study. Routledge.

3. Scodel R (2011) An Introduction to Greek Tragedy. Cambridge, Cambridge University Press.

\section{Your next submission with Juniper Publishers will reach you the below assets}

- Quality Editorial service

- Swift Peer Review

- Reprints availability

- E-prints Service

- Manuscript Podcast for convenient understanding

- Global attainment for your research

- Manuscript accessibility in different formats ( Pdf, E-pub, Full Text, Audio)

- Unceasing customer service

Track the below URL for one-step submission

https://juniperpublishers.com/online-submission.php 